\title{
ANÁLISE DE ASSOCIAÇÃO DA PERCEPÇÃO DE GRAVIDADE DO COVID-19 COM OS HÁBITOS ADOTADOS DURANTE PANDEMIA
}

Elizangela Halinski Cardoso; Universidade Feevale; elizahcardoso@gmail.com Sara Kleinschmitt; Universidade Feevale; sarak@feevale.br Sabina Stedile; Universidade Feevale; sabinastedile@gmail Marcele Medina; Universidade Feevale; marcele.medina@hotmail.com Maristela Peixoto; Universidade Feevale; maristelapeixoto@feevale.br Marcus Levi Lopes Barbosa; Universidade Feevale; marcusl@feevale.br Geraldine Alves dos Santos; Universidade Feevale; geraldinesantos@feevale.br

\section{RESUM0}

Introdução: A pandemia de COVID-19 tem provocado mudanças nas rotinas dos idosos e também em alguns aspectos psicossociais e interpessoais. Neste sentido, a pandemia do novo coronavírus representa um cenário de circunstâncias totalmente sem precedentes, como alterações de hábitos provocadas por ela. Objetivo: Analisar a associação da percepção da gravidade do COVID-19 de pessoas idosas com hábitos desenvolvidos durante a pandemia. Métodos: O estudo foi realizado com 48 pessoas idosas, com mais de 60 anos, de ambos os sexos, através de uma pesquisa de opinião desenvolvida no Google Forms, abordando os hábitos desenvolvidos durante a pandemia nos meses de maio e junho de 2020. Resultados: Na regressão linear pelo método stepwise, realizada com a variável percepção da gravidade do COVID-19 $\left(R^{2}=0,938\right)$, identificou-se uma relação direta entre as variáveis percepção da letalidade do COVID-19, manutenção de hábitos de higiene para a prevenção da H1N1 e uma relação indireta com o desconforto, medo ou preocupação em relação à saudade de pessoa próximas, higienização das compras ao chegar em casa e qualidade do sono durante este período de pandemia. Diante dos dados encontrados, constata-se uma relação entre percepção da letalidade e mudanças de hábitos que os idosos têm durante a pandemia. Desta forma, quanto maior a compreensão sobre a pandemia, mais os participantes alteraram os hábitos, considerando a letalidade. Conclusão: Com esses resultados, é possível avaliar a percepção que as pessoas idosas têm sobre a gravidade do coronavírus, corroborando com as prevenções e mudanças efetivas dos seus comportamentos e hábitos pessoais.

Palavras-Chave: COVID-19; Hábitos; Pandemia. 